\title{
Polarized cells, polarized views: asymmetric cell division in hematopoietic cells
}

\author{
Kim Pham ${ }^{1,2}$, Faruk Sacirbegovic ${ }^{3 \dagger}$ and Sarah M. Russell ${ }^{1,2,3,4}$ * \\ 1 Immune Signalling Laboratory, Peter MacCallum Cancer Centre, East Melbourne, VIC, Australia \\ ${ }^{2}$ Centre for Micro-Photonics, Faculty of Engineering and Industrial Sciences, Swinburne University of Technology, Hawthorn, VIC, Australia \\ ${ }^{3}$ Department of Pathology, University of Melbourne, Melbourne, VIC, Australia \\ ${ }^{4}$ Sir Peter MacCallum Department of Oncology, University of Melbourne, Melbourne, VIC, Australia
}

Edited by:

Francesca Di Rosa, Italian National

Research Council, Italy

Reviewed by:

Salvatore Valitutti, Institut National de la Santé et de la Recherche Médicale, France

Derk Amsen, Sanquin Blood

Research, Netherlands

*Correspondence:

Sarah M. Russell, Immune Signalling Laboratory, Peter MacCallum Cancer

Centre, St Andrews Place, East

Melbourne, VIC 3002, Australia

e-mail: sarah.russell@petermac.org

${ }^{\dagger}$ Present address:

Faruk Sacirbegovic, Department of Biochemistry and Molecular Biology, Monash University, Melbourne, VIC, Australia
It has long been recognized that alterations in cell shape and polarity play important roles in coordinating lymphocyte functions. In the last decade, a new aspect of lymphocyte polarity has attracted much attention, termed asymmetric cell division (ACD). ACD has previously been shown to dictate or influence many aspects of development in model organisms such as the worm and the fly, and to be disrupted in disease. Recent observations that ACD also occurs in lymphocytes led to exciting speculations that ACD might influence lymphocyte differentiation and function, and leukemia. Dissecting the role that ACD might play in these activities has not been straightforward, and the evidence to date for a functional role in lymphocyte fate determination has been controversial. In this review, we discuss the evidence to date for ACD in lymphocytes, and how it might influence lymphocyte fate. We also discuss current gaps in our knowledge, and suggest approaches to definitively test the physiological role of ACD in lymphocytes.

Keywords: cell polarity, asymmetric cell division, immunological synapse, scribble complex, cell fate

\section{INTRODUCTION}

An effective immune response relies on the coordination of signals to control major cell fate checkpoints such as proliferation, differentiation, survival, and death. While many key players, including surface molecules, transcription factors, and cytokines have been identified to be important for immune cell fate control, it is still not clear how these signals are integrated during the differentiation and function of $\mathrm{B}$ and $\mathrm{T}$ cells. These questions of how signals are orchestrated during cell fate determination have been particularly well addressed in progenitor cells of the developing worm and fly. In these two organisms, cell fate is strongly influenced by the asymmetric distribution of fate determinants into the two daughters of a dividing cell, known as asymmetric cell division (ACD) (1). ACD involves the differential partitioning of protein, mRNA, microRNA, and other cellular constituents into the two daughter cells. Therefore, ACD imparts differential fates such as self-renewal, quiescence, proliferation, differentiation, and apoptosis. The mechanisms and consequences of $\mathrm{ACD}$ were initially studied in Drosophila melanogaster neuronal precursors, and $C$. elegans zygote formation, but have now been elucidated in many tissues, including those of mammals. In this review, we describe our current understanding of the mechanisms and consequences of ACD in cells of solid tissues, discuss the evidence that similar processes might apply in hematopoietic progenitor cells, B cells, and $\mathrm{T}$ cells. We also discuss, what will be required to determine whether there are physiological roles for ACD in lymphocyte development, function, and disease.

\section{THE ROLE OF ACD IN SOLID TISSUES}

Homeostasis of stem cells frequently involves ACD, where a parent cell divides to generate a daughter cell identical to itself ("self-renewal"), as well as another daughter that is programed to proliferate, differentiate, or both (1). In some instances, the different fates of the two daughters can occur through stochastic responses in which each daughter has some probability of either self-renewing or adopting a different fate to maintain an appropriate balance of self-renewing and differentiating progeny on a population level. In other instances, the balance between selfrenewal and differentiation is controlled at the single cell level by ACD. An example in which ACD controls the expansion and differentiation of the cells occurs in the developing Drosophila central nervous system (2) (Figure 1A). During development of the larval central nervous system, neuroblasts delaminate from the neurepithelium to undergo up to 20 rounds of ACD, each round creating another neuroblast ("self-renewal") and a ganglion mother cell (GMC) that can further proliferate and differentiate to form mature neurons. Neuroblasts become quiescent during pupation but then re-enter the cell cycle and reinitiate ACD for further rounds of proliferation and differentiation (1). The limited set of neuroblasts therefore undergoes controlled ACD that contributes to the thousands of adult neurons and neuronal associated cells of the central nervous system.

ACD plays a dominant role in dictating fate in C. elegans, starting at the first zygotic division after fertilization, when the fertilized egg divides asymmetrically to produce an anterior $\mathrm{AB}$ cell and a 


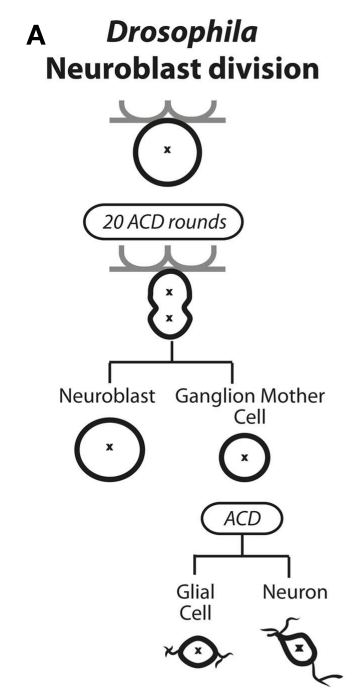

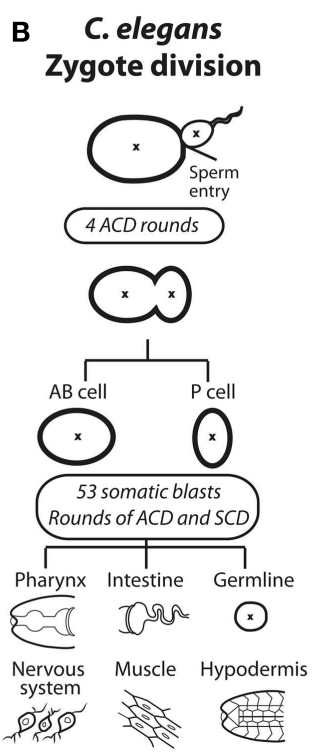

\section{Mammals \\ Neuronal precursor division}

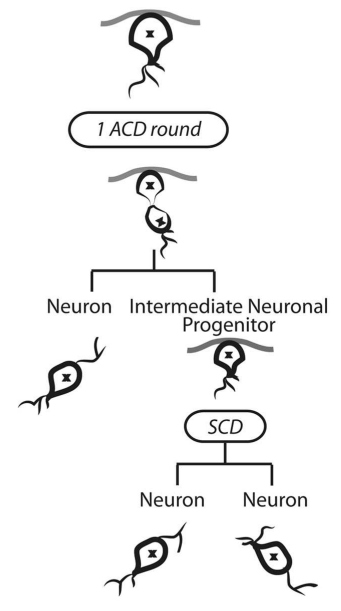

FIGURE 1 | Asymmetric cell division in solid tissues of (A) Drosophila, (B) C. elegans, and (C) Mammals. (A) In Drosophila, selected neuroblasts undergo up to 20 rounds of asymmetric cell division (ACD). The asymmetric distribution of polarity and cell fate determinants causes spindle asymmetry to result in a large self-renewing neuroblast cell and a smaller ganglion mother cell (GMC). The GMC undergoes a subsequent ACD to produce a glial cell and a neuron. (B) ACD during zygotic division in C. elegans. The site of sperm entry serves determines the asymmetric distribution of polarity and cell fate determining proteins as well as spindle asymmetry. During the embryonic stage four rounds of ACD results in the emerging anterior body $(A B)$ and posterior $(P)$ cells. During the larval stage, 53 somatic blasts undergo bursts of ACD and symmetric cell division (SCD), specifying all future posterior or soma fates in various tissues. (C) Neuronal precursor asymmetric division in mammals. The first asymmetric cell division produces a neuron and an intermediate neuronal precursor (INP), which undergoes a symmetric division to produce two neurons. posterior P1 cell (Figure 1B). Four rounds of ACD follow; each producing one daughter that contributes only to soma and the other only to the germline. Thus, ACD controls differentiation and influences the expansion of cells from one generation to the next (3). ACD also occurs in mammals during brain and gut development. During brain development, a burst of symmetric cell divisions (SCDs) increases the progenitor pool, then sequential ACD in the neurepithelium balance self-renewal with differentiation of cells committed to the neuronal lineage (Figure 1C) (4). During mammalian gut development, in particular the colonic crypt, there is a high turnover of tissue where up to $10^{10}$ mature gut cells are replenished using a balance of symmetric and asymmetric divisions $(5,6)$. Within the folds of epithelium lining the colon, crypt cells continually undergo ACD to self-renew and generate proliferative daughter cells that terminally differentiate and transiently populate the migrating compartment, then die. ACD in mammals has also been observed during the development and differentiation of muscle, mammary glands, and skin (7-12). The mechanisms guiding these decisions in mammals are not well understood, but many molecular players that were identified in C. elegans and Drosophila, as discussed in the next section, have also been implicated in mammalian ACD.

An interesting aspect of ACD is the varied extent of influence that has been observed in different developmental systems. ACD is absolutely required during zygotic development in C. elegans, where the molecular differences between the daughter cells directly specify their different fates (13-18). In contrast, ACD of Drosophila nervous system is not (or less) deterministic, as subsequent fate decisions are subject to influences from the microenvironment [reviewed in Ref. (19)]. In some instances, the primary molecular consequence of ACD is a difference in signaling between the two daughter cells. Rather than specifying the differentiation path for the two daughter cells, this merely ensures that the two daughter cells adopt different fates from each other in response to external influences $(20,21)$. Context can play another important role by controlling whether a cell divides symmetrically or asymmetrically. In contrast to the prescriptive pattern in C. elegans, where the early divisions are uniformly asymmetric, cell divisions in the mammalian developing nervous system can switch from symmetric to asymmetric to selectively expand specific cellular pools, or to generate more differentiated cell types as the need arises $(22,23)$.

\section{MOLECULAR REGULATION OF ACD}

ACD involves three processes: (i) cellular cues to dictate the axis of polarity; (ii) opposing actions of polarity proteins to dictate molecular differences along this axis; and (iii) the alignment of the mitotic spindle with the polarity axis to maintain asymmetry during division (Figure 2). Many of the proteins involved in establishing polarity and aligning the mitotic spindle are evolutionarily conserved, but differences occur in the cues that dictate the orientation of polarity, the composition of the polarity modules, and the fate determinants that dictate the differences in the functional outcome in different cell types. Here, we focus on the Drosophila central nervous system to illustrate the principles of mutual antagonism and connectivity with the spindle pole that are required for ACD (Figure 3A). 


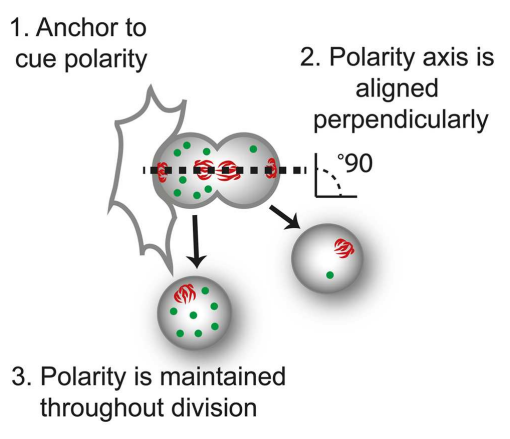

FIGURE 2 |The three requirements of asymmetric cell division. For control of progeny proliferation, death, and differentiation during asymmetric cell division $A C D$, three requirements must be fulfilled; (1) an anchor to dictate the axis of polarity, in this case another cell; (2) the dividing cell is aligned along the axis of division, usually perpendicular to the anchor (perpendicular orientation shown by the alignment of mitotic spindle, red); and (3) that polarity of the protein (green) is maintained throughout division.

Asymmetric cell division and segregation of cell fate determinants in Drosophila neuroblasts is regulated by the interactions between the Scribble and Bazooka (Par3 in mammals) polarity complexes. Through the interaction with the $\mathrm{G} \alpha_{i}$ complex, the Scribble and Bazooka complexes also coordinate the orientation of the mitotic spindle. During ACD, the Bazooka and $\mathrm{G} \alpha_{i}$ complexes are linked via an adaptor protein, inscuteable, and polarize to the apical cortex of the dividing cell (24-26). In addition, Dlg (from the Scribble complex) binding to the plus-end directed microtubule motor protein Khc-73 (Kinesin heavy chain 73) and Pins regulates the positioning of the $\mathrm{G} \alpha_{i}$ complex $(27,28)$.

The mechanism by which the Par3/Bazooka and Scribble complex delineate the two poles of the cell is not yet clear, but it is thought to involve the regulation of aPKC phosphorylation activity by Lgl. The activity of aPKC is inhibited when it is in a complex with Par6 and Lgl (part of the Scribble complex) (17, 18). During mitosis, Par6 is phosphorylated, which relieves the repression of aPKC activity and allows aPKC to phosphorylate and release $\mathrm{Lgl}$ from the complex. This in turn allows the restriction of aPKC localization to one side of the cell cortex, where it is free to phosphorylate and release the cell fate determinants such as Numb from that side of the cortex $(29,30)$. One key observation is that while proteins of the Par3/Bazooka and Scribble complex localize at the apical side during early neuroblast division, some members of these complexes disperse cortically at telophase (6). Moreover, mutations in scribble or $l g l$ do not affect Dlg polarization, but Dlg is required for the cortical recruitment and polarization of both Scribble and $\operatorname{Lgl}(6)$.

The role of ACD in steering fate determinants preferentially into one daughter cell is illustrated by the phenotypes in Drosophila in which the polarity and spindle regulators are mutated. For instance, the loss of $l g l$ results in loss of asymmetric recruitment of fate determinants such as Numb in neuroblasts $(6,31,32)$. Mutations in scribble, $d l g$, or $l g l$ lead to mislocalization of multiple basal cell fate determinants and disrupt orientation of the mitotic spindles, which results in perturbed cell size and decreased GMC fate specification. In contrast to $l g l$ mutations, mutations in $a P K C$ lead to reduced neuroblast proliferation (33). Interestingly, the neuroblast hyperproliferation and mislocalization of cell fate determinants that is associated with $l g l$ mutant flies can be partially rescued when crossed with apkc mutant flies (34), indicating that interactions between aPKC and Lgl specify respective cell fates. Other studies have also identified that Numb is a substrate for aPKC, and that aPKC-mediated phosphorylation is critical for the asymmetric segregation of Numb and the specification of neuroblast fate $(29,30,35)$. Other genetic and biochemical assays show that Numb directly binds to the intracellular domain of the cell fate determinant, Notch. It is postulated that Numb acts as a negative regulator by mediating Notch degradation via endocytic pathways mediated by alpha-Adaptin, a component of the clathrin associated endocytosis pathway, which targets proteins for endocytosis $(36,37)$.

\section{DOES ACD OCCUR IN THE HEMATOPOIETIC SYSTEM?}

As with the numerous fate choices governing Drosophila neuroblast fate, all cells of the hematopoietic system make fate decisions related to differentiation, proliferation, death, and self-renewal. It would seem reasonable that cells of the hematopoietic system should also adopt the process of ACD as a means of controlling such decisions. Elucidating a possible role for ACD in fate determination of hematopoietic cells, however, has been slower than elucidating the role for ACD in cells of solid tissues. First, the seminal work in model organisms such as C. elegans and Drosophila is more readily applicable to solid tissues in mammals, where the cue and fate determinants are often conserved across species (Table 1). For instance, elucidation of ACD in mammalian neurons has benefited directly from findings in Drosophila, but there is no Drosophila parallel to guide studies in the hematopoietic system. Second, most progress has been made in systems, where the entire developmental program can be tracked and correlated with molecular behavior during and subsequent to each cell division. This has been the case with $C$. elegans, where more than three decades of research effort has been invested into exploring the mechanisms by which ACD regulates development of the C. elegans embryo by time lapse microscopy (38). Similarly in Drosophila, two decades ago direct observations that Numb was recruited into the GMC upon division were reported, and that levels of Numb dictate neuronal differentiation (39).

Frustratingly, longitudinal analyses in vivo are still not conceivable for ACD in the hematopoietic system because morphology is less informative (size differences do not indicate subsequent fates) and the cells are highly motile (cannot be tracked in vivo over generations). Also, differentiation generally occurs gradually over a longer time period. Instead, we have relied so far on correlative findings, each of which contributes to, but does not definitively prove the notion that ACD in cells of the hematopoietic system, including lymphocytes impacts upon cell fate decisions. Experiments to explore a role for ACD in cells of the hematopoietic system such as HSC, and lymphocytes such as $\mathrm{B}$ cells and $\mathrm{T}$ cells, so far have involved seeking three lines of evidence:

1. Evidence of a bifurcation in cell fate in the daughter cells of a dividing hematopoietic cell; 


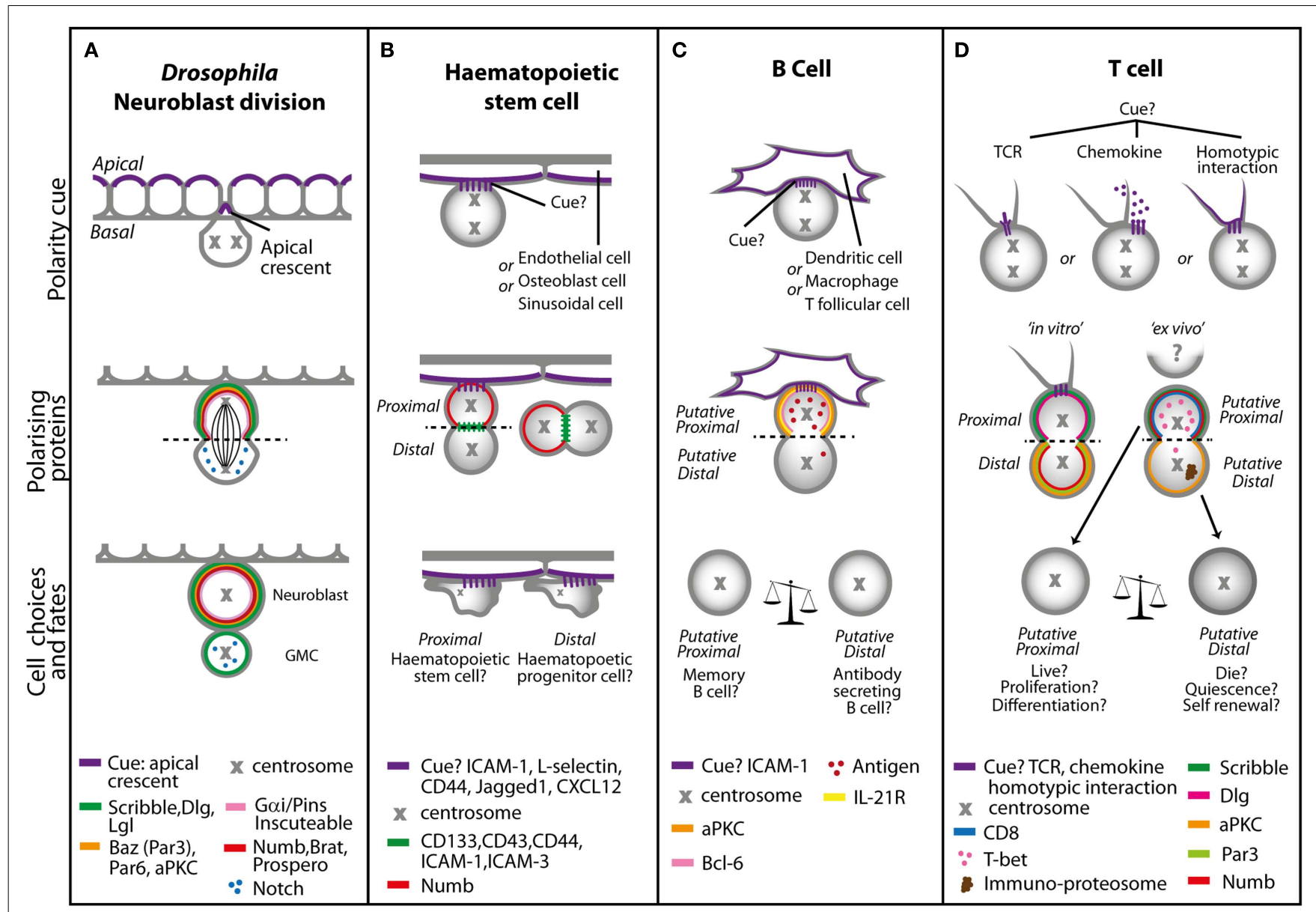

FIGURE 3 | Models of asymmetric cell division in (A) Drosophila neuroblasts, (B) hematopoietic stem cells, (C) B cells, and (D) T cells

(A) In Drosophila, neuronal precursors delaminate from the neurepithelium to undergo ACD. The polarity cue is the apical crescent, and during early division duplicated centrosomes rotate $90^{\circ}$ to create the distinct apical and basal sides that are mediated by the Scribble and Bazooka polarity protein complexes. During late division, the coordination of the spindle length by $\mathrm{G} \alpha_{\mathrm{i}}$ signaling and proteins such as Inscuteable and Pins result in asymmetric distribution of cell fate determinants, such as Numb, Notch, Brat, and Prospero. The coordination and maintenance of signaling results in a self-renewing neuroblast cell and a ganglion mother cell (GMC). In cells of the hematopoietic system, multiple polarity cues can dictate asymmetric cell division. (B) Hematopoietic stem cells migrating in a stem cell niche in the bone marrow can receive adhesion, Notch or chemokine cues from surrounding endothelial, osteoblast, or sinusoidal cells, resulting in asymmetric distribution of cell fate determinants such as Notch and Numb (during attachment with the interacting cell or separately) to produce a self-renewing hematopoietic stem cell and a hematopoietic progenitor cell, which will go on to differentiate. In (C) B cells and (D) T cells the polarity cue might be through interaction with macrophages, other $T$ cells and antigen presenting cells such as dendritic cells via adhesion, chemokine, or TCR molecules. This interaction sets an axis of division and asymmetric distribution of several surface molecules, antigen polarity, and cell fate determinants. In B cells daughters proximal to the interacting cells favor memory B cell fate, as well as more potent T cell activators and proliferators. Distal B cell daughters favor antibody secreting cell fate, with moderate $T$ cell activating and proliferative capabilities. In the absence of ICAM-1, B cell fate is altered toward memory B cells at the expense of antibody secreting B cells. T cell daughters will inherit factors that will increase or decrease their propensity to adopt a variety of fates including that of a memory or effector $T$ cell.
2. Evidence of asymmetry in dividing hematopoietic cells (defining the polarity cue and the fate determinants that are asymmetrically distributed);

3. Evidence of fate alterations upon disruption of the control of ACD.

The burden of proof lies in trying to combine these approaches to demonstrate in the same system that both ACD and fate bifurcation occurs, that ACD is associated with cell fate decisions by the daughter cells, and that both are disrupted by deregulation of a cell polarity regulator.

\section{ACD IN HSC}

As with all stem cells, it is well accepted that blood homeostasis involves a bifurcation in HSC fate whereby one daughter of an HSC is a copy of the parent (self-renewal) and the other expands and differentiates to give rise to the many blood lineages. There is growing acceptance that HSC may also undergo ACD to regulate fate choices, and the cues that might regulate ACD have been well established $(38,40)$. HSCs interact with a niche within the bone marrow, fetal liver, and peripheral blood, which could provide polarity cues to mediate ACD for fate determination (41). For example, the osteoblasts in bone marrow can 
Table 1 | Known functions of polarity proteins in lymphocytes.

\begin{tabular}{llr}
\hline Polarity protein & Known phenotypes & Lymphocyte phenotype \\
\hline PAR-1 & - Mutation (C. elegans): controls spindle positioning (12) & - Dominant negative mutation (T cells): loss of Par1b \\
PAR-1 & - Mutations (Drosophila): failed oocyte polarity. Phenotypes can be & polarization and TCR-induced MTOC polarization (111) \\
Par1b/MARK2/EMK & rescued by expressing ParN1 isoforms (121) & - Loss (B and T cells): normal B and T cell development. \\
& & CD4+ T cells exhibit higher TCR activation, B cell \\
& & T-dependent and T-independent responses are altered, \\
& & suggesting autoimmunity (112)
\end{tabular}

PAR-3 Mutation (C. elegans): posterior shift during P0 asymmetric cell

Bazooka

Par3, ASIP, PARD3 division (15)

- Mutation (Drosophila): loss of apical cue for Inscuteable localization in asymmetrically dividing neuroblasts (25)

- Loss (Drosophila): disruption of embryo basolateral membrane polarity during mid-gastrulation (122), mislocalization of Numb, and planar symmetry of pl cell during sensory organ precursor ACD (123) failed oocyte ACD (124)

- Removal/ectopic expression (mammalian neocortex): reduction of ACD and transformation of glial progenitor fate (57)
PAR-6

Par6

Par6 $\alpha, \beta$, and

$\gamma /$ PARD6 A, B, and G
- N/A. Par3 is excluded from the T cell uropod, and may localize transiently to the synapse during immunological synapse formation (78)
Pkc-3 Mutation (C. elegans): posterior shift during PO division (15)

Atypical PKC

$\mathrm{PKCl} / \lambda$ and $\zeta$

- Knockdown (Drosophila): reduced cell proliferation in both neuroblasts and epithelia $(34,125)$
- Mutation (Drosophila): failure of oocyte differentiation (45)

- Loss (Drosophila): loss of AB cell polarity (126), failed oocyte ACD (124)
- Overexpression of Par6 N-terminal aPKC interacting domain reduces $T$ cell uropod formation (106)
- Overexpression/dominant negative mutation (T cells): randomizes F-actin distribution, impairs uropod formation, motility, defects in T cell scanning $(106,127)$

- Drug inhibition of aPKC/Par6 interaction (T cells): defective Numb localization during T cell ACD (94)

- Loss: delay in secondary lymphoid organ formation (66), no naive T cell defects, Th2 differentiation but not Th1 differentiation is impaired, inhibition of ovalbumin induced allergic airway disease (108)

- Combined PKCl/ $\lambda / \zeta$ loss (HSC's, B and T cells): normal HSC self-renewal, engraftment, differentiation, interaction with the bone marrow microenvironment, polarization, self-renewal. Normal mature B cells and T cells numbers (56)

\section{Crb-1/Crb-like}

Crumbs

Crumbs1-3
- Mutations (Drosophila): loss of epithelial cell morphology in the ectoderm (128)

- Ectopic expression of Crumbs3 (mammalian epithelia): loss of tight junction formation and intracellular polarity (129)
C01B7.4/tag-117

Stardust

Pals1/MPP5
- Loss (single and combined with Crumbs loss, Drosophila): disruption of the establishment and maintenance of epithelial morphology in the embryo (130), disrupted embryonic basolateral membrane polarity during mid-gastrulation (122)

- Knockdown (mammals): loss of MDCK cell polarization in confluent cellular monolayers (129)
- Knock down (T cells): suboptimal T cell activation and proliferation. Strongly localized to the Golgi apparatus, and is mislocalized upon Bref A (Golgi disrupting) treatment (55) 


\section{Table 1 | Continued}

\begin{tabular}{|c|c|c|}
\hline Polarity protein & Known phenotypes & Lymphocyte phenotype \\
\hline $\begin{array}{l}\text { Let-413 } \\
\text { Scribble } \\
\text { Scribble }\end{array}$ & $\begin{array}{l}\text { - Mutations (Drosophila): reduced neuroblast size, increased } \\
\text { ganglion mother cell size, defects in targeting cell fate } \\
\text { determinants, and altered spindle asymmetry (6) } \\
\text { - Loss (Drosophila): defects in junction formation and epithelial } \\
\text { organization. Hyperproliferation, formation of solid tumors in } \\
\text { imaginal disk and follicular epithelia (121) }\end{array}$ & $\begin{array}{l}\text { - Knockdown (T cell line): prevention of TCR receptor } \\
\text { polarization in response to antigen presentation, } \\
\text { reduction in migration due morphological changes } \\
\text { resulting in reduction of uropod formation (78) } \\
\text { - Knockdown (thymocyte): defects in cell-cell clustering } \\
\text { and maturation (77) } \\
\text { - Loss: (T cells): altered pERK signaling in T cells but } \\
\text { responses to influenza infection are intact. (B cells): } \\
\text { delayed B cell proliferation, but T dependant and T } \\
\text { independent activation are normal (63) }\end{array}$ \\
\hline
\end{tabular}

\begin{tabular}{ll}
\hline Dig-1 & Mutation (Drosophila): imaginal disk hyperproliferation, \\
Disks large & tumorogenesis, and transform into solid tumors (131), defects in \\
Dig 1-4 & neuroblast size and mitotic spindle asymmetry (6)
\end{tabular}

- Overexpression (T cells): attenuates basal and Vav1-induced NFAT reporter activation (92)

- Knockdown (T cells): enhances both CD3- and superantigen-mediated NFAT activation (89, 90, 92). Accumulation of actin at the T cell synapse, altered production of Th1 and Th2 cytokines (68)

- Loss (thymocytes and T cells): normal T cell development $(63,68)$. Variable defects in mature $\mathrm{CD}^{+}{ }^{+} \mathrm{T}$ cell differentiation $(68,92)$ Normal TCR-induced early phospho-signaling, actin-mediating events, proliferation, (68)
Lgl-1
Lethal Giant Larvae
- Mutation (Drosophila): defects in neuroblast apical cell and spindle Lgl1, Lgl2 pole size resulting in symmetric or inverted neuroblast cell divisions. Loss of polarity in tissues that leads to overproliferation and tumor growth $(5,132)$
- Loss (mammals): neural progenitor cells fail differentiation, fail to exit cell cycle, then over proliferate and result in neural ectodermal tumors. Mislocalization of Numb in the neuroectoderm of the tumors (133)

Homologs: C. elegans, Drosophila, Mammals.

express Notch ligands such as Jagged-1, adhesion molecules such as ICAM-1/LFA, L-selectins, and CD44, and also express chemokines such as CXCL12 (3) (Figure 3B). Initial evidence that ACD might occur in HSC came from Reya and colleagues, who provided preliminary evidence of asymmetric distribution of Numb in HSC treated with nocodozole to block cells in mitosis. This observation is difficult to reconcile with findings that hematopoiesis seems completely normal in Numb and double numb-numblike conditional mutants $(42,43)$ and in mice with deletion of Numb-like combined with hypomorphic alleles of numb that produce 5-10\% of Numb protein (44-46). Possible explanations for this apparent discrepancy include: incomplete deletion of Numb [recombination at the Numb locus can be context specific (47), and an incomplete deletion of Numb/Numb-like might still leave a few wildtype hematopoietic progenitors to undergo normal lymphoid lineage development, as one or few HSC can repopulate the entire hematopoietic system $(48,49)]$; or that the Numb allele under investigation deletes only exons 5 and 6 and so might not act as a complete null in hematopoietic tissues (50). Another explanation might relate to the notion that $\mathrm{ACD}$, rather than impacting the levels of proteins in individual cells, might create differences in expression levels between neighboring cells to influence fate (51). In this case, mutant alleles that could not segregate asymmetrically might be more informative than mere deletion of the gene. Regardless, an exciting finding from the Reya study was that by using a fluorescent reporter of Notch signaling and time lapse imaging of paired daughters, they showed that HSC can produce daughters with different Notch signaling capacities, and that the proportion of HSC with differential Notch signaling in the daughters differed depending upon the stromal cells with which they were cultured (52).

Work from the Sauvageau laboratory using gain-of-function in vitro and in vivo assays found a component of the endosomal AP-2 complex, alpha-Adaptin (encoded by the Ap2a2 gene), to endow in vivo proliferative advantage and an increase in in vitro HSC maintenance (53). Given that alpha-Adaptin is also important for ACD in Drosophila neuroblasts and sensory organ precursors, these findings suggest that mechanisms of fate determination through ACD could be evolutionarily conserved in HSC. In support of this notion, time lapse imaging of HSC containing 
fluorescently-tagged alpha-Adaptin showed asymmetric inheritance in approximately 50\% of HSC divisions. Knockdown of alpha-Adaptin did not affect HSC proliferation, differentiation, homing or apoptosis, despite alpha-Adaptin mRNA expression being fourfold to eightfold higher in long-term HSC than in intermediate term HSC. Interestingly, alpha-Adaptin and Numb were not co-localized in HSC, unlike in Drosophila neuronal precursors (54), highlighting possible divergent mechanisms of cell fate control.

Besides these two studies, remarkably little is known of the mechanisms by which ACD of HSC might be regulated. Perhaps because cell division of an HSC is, by definition, an extremely rare event, there has been little imaging to determine what molecules are localized asymmetrically at the time of division. The role of polarity proteins in controlling cell fate in HSCs has not yet given a strong indication of the importance of ACD in hematopoiesis. While RNA interference of the Par3 complex proteins, Par6 and PKC $\zeta$ can impair HSC repopulation (55), single and double knockouts of $\mathrm{PKC} \zeta$ and $\mathrm{PKCl} / \lambda$ have no effect on HSC function, in primary and secondary engraftment (56). Adding to this confusion is that aPKC phosphorylates and regulates the Scribble complex protein, Lgl, and loss of Lgll leads to enhanced engraftment and better HSC repopulation capacity due to increased proliferation (57). The evidence to date is therefore suggestive rather than definitive that ACD might control aspects of HSC self-renewal and differentiation.

\section{ACD IN B CELLS \\ ARE THERE BIFURCATIONS IN B CELL FATE THAT COULD BE INFLUENCED BY ACD?}

B lymphocyte development involves fate choices such as proliferation, self-renewal, and differentiation to result in the formation of memory B cells, and plasma cells that produce antibodies of unique specificity (58). Duffy and colleagues recently produced the most exhaustive study to date to determine whether the daughter cells of a dividing B cell exhibit asymmetric fates (59). Time lapse analysis of differentiation, death, and time to next division imaged from one cell division to the next, showed that daughters from $\mathrm{B}$ cell divisions stimulated by interleukin-4 (IL-4) and IL-5 largely undergo symmetrical fates. Interestingly, a small proportion of B cell divisions displayed asymmetric cell fates in which one daughter died and the other survived. The authors determined that the discrepancy in fate observed in this fraction was not a result of asymmetric programing but of the internal competition for fates within each cell. In this model, which is well supported by examples across many species, each cell is programed for "time to die" and "time to divide," and these times are reset upon each cell division (60-62). Similarly, in the B cell study, the "time to die" and "time to divide" were set very close together, such that in some instances the two daughter cells from a single B cell had an equal probability of adopting either fate. This study argues against ACD controlling B cell fate. It should be noted that the symmetrical fate observed here was in the context of soluble activating factors, rather than a directional cue, so does not discount a role for ACD in other forms of B cell activation. In line with the Duffy et al. study, our time lapse analysis of B cells stimulated with another soluble agent lipopolysaccharide also argued against ACD (63).

\section{IS THERE EVIDENCE OF POLARITY IN DIVIDING B CELLS?}

In support of the notion that $B$ cells could receive instructional cues through engagement with dendritic, macrophage, or T helper cells to dictate downstream fates via ACD, Barnett and colleagues explored polarity in the germinal center (64). Dividing B cells within the germinal center asymmetrically localized the transcription factor Bcl6, the receptor for IL-21, and the polarity protein PKC $\zeta$ (64). Asymmetry of these proteins during division required constant signaling through contact with antigen presenting cells, possibly via adhesion through LFA-1/ICAM-1. In ICAM-deficient mice, B cells did not efficiently polarize Bcl6 or PKC $\zeta$, and showed a defect in the number of antibody secreting plasma cells. The evidence of polarity at division, and the correlation of loss of polarity with cell fate differences caused by loss of ICAM-1 (which might have many non-polarity related effects), is compatible with the notion that germinal center B cells undergo ACD to influence cell fate, but further quantification and evidence that the polarity is controlled rather than stochastic, is required to confirm this.

In a separate study, multi-photon microscopy of explanted lymph nodes showed that B cells acquired antigen from macrophages in a polarized manner in vivo, and that the acquired antigen could accumulate preferentially in one daughter cell after $\mathrm{B}$ cell division (65). Antigen asymmetry persisted for up to three rounds after $B$ cell division, and, statistical modeling predicted that up to $25 \%$ of B cells undergo asymmetric inheritance of antigen. There was no evidence for involvement of a polarity cue, or of the molecules involved in polarity, suggesting that the asymmetry of antigen inheritance was more likely a stochastic response than a result of ACD (Figure 3C).

\section{WHAT IS THE PHENOTYPE OF POLARITY-DEFICIENT B CELLS?}

As with the fate tracking information above, analysis of polaritydeficient $\mathrm{B}$ cells provides evidence both for and against a role for ACD (Table 1). Mice deficient in PKC $\zeta$ exhibited subtle delays in $B$ cell development, but these defects were normalized in older mice (66). The B cells from 4- to 6-week-old PKC $\zeta$-deficient mice also show severe defects in in vitro proliferation, enhanced ERK signaling in response to B cell receptor cross-linking (but not in response to non-B cell receptor stimuli), could mount a normal $\mathrm{T}$ independent humoral response in vivo, and showed slight defects in T-dependent humoral responses (67). B cell development is grossly normal in the absence of $\operatorname{Dlg} 1(63,68)$, Lgl1, and Scribble (63), although a recent paper suggests that Dlg1-deficient B cells, like PKC $\zeta$-deficient B cells, exhibit developmental defects in young mice that are rescued in older mice (69). Knockdown of Dlg1 (also called SAP97) in B cells in vitro impaired the formation of the immunological synapse and inhibited BCR-dependent responses (70). Scribble-deficient mice have intact in vitro and in vivo humoral responses to activation and infection respectively, but again show perturbed kinetics of ERK phosphorylation (63) as previously seen in epithelial tissues when Scribble is depleted (71-73). Combined, these data do not provide compelling support for a role for ACD in B cell development or responses. The hints of $\mathrm{B}$ cell phenotypes in some knockouts, and the observations that these phenotypes diminish with age, suggest that compensatory mechanisms that might make combined or more acute deletions 
necessary to determine the role of ACD in B cell development and function.

\section{ACD IN T CELLS}

\section{ACD IN THYMOCYTES}

A small number of observations suggest that polarity proteins, and perhaps ACD, might also play a role in developing T cells. Nearly 50 years ago, the proportions and kinetics of proliferation of three types of thymocytes, as distinguished by their size, were assessed using autoradiographic analysis of tritiated thymidine uptake, and the data fit a requirement for ACD (74). This was followed by microscopic evidence of asymmetry at division, as defined by differences in the cytoplasmic or nuclear size in the two daughters in several species including the mouse (75). The involvement of polarity proteins was shown in in vitro interactions between thymocytes and dendritic cells, where Dlg1 was rapidly polarized to the synapse following TCR activation (76). Pike and colleagues demonstrated that in vitro DN3 thymocyte development was perturbed by knockdown of Scribble, with an accumulation of DN3 thymocytes and inefficient double positive $\mathrm{CD} 4^{+} \mathrm{CD} 8^{+}$thymocyte generation (77). Interestingly, depletion of Scribble affects DN3 thymocyte clustering by limiting the polarization of the integrin ICAM-1/LFA-1 $(77,78)$. In a study by Aguado and colleagues, the transgenic expression of wildtype or dominant negative forms of Numb result in altered DN3 thymocyte pre-TCR signaling, proliferation, and differentiation (79). Asymmetry of Numb was also proposed by this group as a mechanism for these signaling and fate differences, but asymmetry was not rigorously assessed. Taken together, these studies provide hints that polarity and cell fate proteins are important for aspects of $\mathrm{T}$ cell development and downstream fate choices. Careful analysis of protein localization at division, and correlation of any asymmetry with alterations in fate, will be required to elucidate a possible role for ACD in thymocyte differentiation.

\section{ARE THERE BIFURCATIONS IN T CELL FATE THAT COULD BE INFLUENCED BY ACD?}

Perhaps the most studied and most controversial aspect of lymphocyte $\mathrm{ACD}$ is in mature T cells. In part, the controversies are due to the elusive nature of the fate choices that a naïve $\mathrm{T}$ cell makes upon stimulation by an antigen presenting cell. $\mathrm{CD} 4^{+}$cells can differentiate along many pathways upon stimulation (80), but will not be discussed in detail here as the role of ACD in $\mathrm{CD} 4^{+}$differentiation has not been extensively pursued. $\mathrm{CD} 8^{+}$naïve $\mathrm{T}$ cells give rise to both effector and memory progeny, and many subpopulations within these categories. A bifurcation of fate decisions by the two daughters of a naïve $\mathrm{CD} 8^{+}$cell would be an appealing explanation for how one naïve $\mathrm{T}$ cell can yield both effector and memory populations (81). Despite the wealth of literature on the subject, it is still not clear exactly when the two lineages arise from a naïve $T$ cell, and for instance whether (and how far) memory cells progress down the effector differentiation pathway before committing to a memory fate (82-84).

Several recent papers provide support for the notion that fate is controlled at many stages during T cell activation, including the time of first division, when ACD could play a role. Three recent studies assess the progeny of individual $\mathrm{CD} 8^{+}$clones in vivo and made two important observations (85-87). First, a striking diversity in number of progeny (over 1000-fold) from individual clones was observed, indicating a remarkable degree of variation in the naïve $\mathrm{T}$ cell responses. Whether this variation was the result of cell intrinsic programing of the naïve precursor, stochastic responses to activation, or differences in the microenvironment, was not clear. Second, even within individual clones, disparity in fate decisions was observed with some naïve precursors giving rise to uniform progeny, and others giving rise to progeny that had variable effector and memory characteristics. The data from one of these studies assessed 304 possible models for progression between naïve, effector, central memory and effector-memory states, and found only two of the models to fit their data, one of which allowed for ACD in the control of cell fate and the other did not (86). To support the notion that decision making could occur at multiple stages of $\mathrm{T}$ cell activation, limiting dilution, and short term progeny analysis demonstrated that $\mathrm{T}$ cell fate determination occurs before, during, and after the first $\mathrm{T}$ cell division (30).

\section{IS THERE EVIDENCE OF POLARITY IN DIVIDING T CELLS?}

It is now well established that in mature T cells, activation of the TCR triggers recruitment of polarity proteins (Scribble, Dlg1-4, PKC $\zeta)$ to the immunological synapse $(36,88-93)$. Chang and colleagues contributed the first of steadily mounting evidence that mature $\mathrm{T}$ cells polarized polarity proteins during mitosis (94). Mitotic $\mathrm{CD}^{+} \mathrm{T}$ cells undergoing their first division following Listeria infection demonstrated asymmetric polarization of several polarity proteins including Scribble and $\mathrm{PKC} \zeta$, the cell fate determinant Numb, and surface molecules important for $\mathrm{T}$ cell function such as CD8. This asymmetry was dependent upon the adhesion molecule, ICAM-1, and when populations of daughter $\mathrm{T}$ cells from the first division were sorted on the basis of differential CD8 expression and injected into Listeria-infected mice, mice receiving daughter cells with lower surface CD8 cleared the delayed infection more efficiently (94). This suggested that ACD could control memory differentiation in $\mathrm{CD} 8^{+} \mathrm{T}$ cells, although it has not yet been determined whether the disparate $\mathrm{CD} 8$ levels were a direct consequence of ACD. The finding that the transcription factor, T-bet, was asymmetrically partitioned into the daughters preferentially expressing CD8 provided support for the notion that ACD controls key fate determinants for effector memory decisions (95). This study also demonstrated that $\mathrm{CD} 4^{+}$cells display polarity at mitosis (95), and further work by the Reiner group showed that CD8 memory T cells can reinitiate ACD after rechallenge (96). Work by Palmer and colleagues also showed ACD of $\mathrm{CD} 8^{+} \mathrm{T}$ cells, and further demonstrated that peptide affinity can determine the extent of asymmetry during effector differentiation, and that the extent of asymmetry correlated with pathology (97).

These in vivo studies together provided the first indications that $\mathrm{T}$ cells can undergo ACD. The necessity for fixed staining of cells extracted from lymph nodes, however, means that the context of the cell division is not apparent. Without a defined cue, it is not possible to discriminate between ACD and asymmetry due to stochastic distribution of proteins at the time of division. For instance, it has not been possible to observe in these ex vivo experiments whether the dividing cell was attached to an antigen presenting cell to directly observe the subsequent behaviors of each 
T cell daughter. To address some of these issues, we have established an in vitro assay in which divisions can be observed in the context of interactions with the antigen presenting cell (98). In this system, $T$ cell ACD required sustained contact with the antigen presenting cell but not a sustained immunological synapse. ACD of naïve T cells utilized conserved mechanisms, involving the Par3, Scribble, and Pins complexes to orchestrate spindle orientation. The cell fate determinant Numb was also localized asymmetrically, and disruption of mitotic spindle orientation caused mislocalization of Numb as well as altered memory and effector $\mathrm{T}$ cell fate ratios. Interestingly, there were several differences in protein asymmetry in this study and the ex vivo analyses described above. These include that the TCR and associated proteins were no longer polarized at the time of division in the in vitro system, and differences in the pole to which Numb was recruited. These differences might reflect differences in the experiments, such as ex vivo versus in vitro analysis, and the use of different transgenic systems and/or the use of Cytochalasin in the ex vivo experiments.

It would not be at all surprising for T cell ACD to be highly context dependent, with both qualitative and quantitative differences in ACD depending upon the context of T cell activation. This notion is supported by the study by Palmer and colleagues, in which different peptide ligands caused different degrees of asymmetry in the dividing cells (97). To further complicate the picture, in vivo imaging has suggested that interactions with the dendritic cell are transient around the time of division $(99,100)$, and that homotypic adhesions at this time can play a key role in fate determination $(101,102)$. Perhaps, therefore, some or all of the ex vivo dividing cells that exhibited asymmetry $(94,97)$ were polarized as a result of homotypic adhesions, which also depend upon ICAM-1 (101). A scenario in which ACD of $\mathrm{CD}^{+} \mathrm{T}$ cells could be qualitatively or quantitatively altered depending upon interactions with antigen presenting cells or other lymphocytes is compatible with the requirement that naïve $\mathrm{CD}^{+}{ }^{+} \mathrm{T}$ cells must integrate many signals to orchestrate a robust but fine-tuned response to antigen presentation (103).

\section{WHAT IS THE PHENOTYPE OF POLARITY-DEFICIENT T CELLS?}

Initial studies utilizing knockdown approaches to reduce the expression of Scribble complex proteins suggested that they played important roles in the development and function of T cells. T cells with reduced Dlg1 and Scribble showed impaired polarity and signaling in response to antigen presentation $(78,89,90,104)$, and impaired regulatory $\mathrm{T}$ cell function (105) as well as the developmental defect described above (77). In contrast, the analysis of $\mathrm{T}$ cells from mice with deleted polarity genes has shown either no, or very subtle, phenotypes. Expression of kinase dead forms of aPKC results in a reduction of polarization during migration and scanning (106), yet mice deficient in the atypical PKC isoforms PKC $\zeta$ or $\mathrm{PKCl} / \lambda$ have an intact mature $\mathrm{T}$ cell repertoire, and normal responses with the exception of a defect in Th1 responses $(56,107-$ 110). Mice deficient in Parlb exhibit alterations in CD44 expression on CD4 T cells, which might reflect aberrations in memory development, and this correlates with an involvement of Parlb in T cell polarity $(111,112)$. Three independently generated mice deficient in Dlg1 also exhibited normal T cell development and function, although again a defect in Th1 responses was observed in one mouse (68). Interestingly, the Th1 defect was observed in acute knockout (gene deletion driven by the CD4 promoter) and knockdown $\mathrm{T}$ cells, but not in $\mathrm{T}$ cells where the gene had been deleted in HSC, suggesting that compensatory mechanisms can occur during development to mask polarity-deficient phenotypes (68). In another study, Dlg1-deficient mice showed normal development and proliferative response, but a subtle change in the expression of CD44, 10 days after immunization, suggestive of a skewing of central and effector memory responses that was supported by differences in IL-2 production in immunized mice (113). Similarly, T cell development in Scribble and Lgll deficient mice was normal, as were the responses of Scribble-deficient mice to an influenza infection (63). Together, these studies indicate that the polarity proteins are not essential for HSC, T or B cell development and function, but that subtle effects can arise under some circumstances (Table 1).

A model for T cell ACD fate that links these findings could be as follows (Figure 3D). The polarity cue could derive from an interaction between the $\mathrm{T}$ cell and the antigen presenting cell or from homotypic interactions. A sustained immunological synapse may not be needed, but other molecules on the antigen presenting cell or the homotypic T cell, or chemokines might provide polarity cues. Quantitative and qualitative aspects of polarity at mitosis could be influenced by several factors such as the affinity of the TCR-MHC interaction, the duration of contact with the antigen presenting cell, the availability of other T cells for homotypic interactions. Partitioning of molecules, such as Numb and T-bet, differentially into one daughter cell would then cooperate with other signals from the microenvironment to fine tune the differentiation response.

\section{FUTURE/CONCLUDING REMARKS}

Much more work is needed to reconcile the differences in phenotypes between different studies of polarity-deficient mice, and to determine whether or not immune defects in polarity-deficient mice are due to defects in ACD. The effect of knockout or knockdown of several polarity regulators has now been assessed, and the general picture is that the most striking phenotypes occurred with acute knockout or early in development, with emerging evidence that compensatory mechanisms can occur with time. Furthermore, no publications yet have indicated a correlation between these defects and evidence of asymmetry at mitosis, so it is not possible to definitively ascribe any of the phenotypes to a defect in ACD. In support of a role for ACD in immune cell development and function, some correlations are now emerging in which alterations in ACD are associated with alterations in fate. In this light, the relationship between ACD and pathology discovered by the Palmer group (97) is very encouraging. Similarly, inhibition of aPKC by the drug aurothiomalate ("Gold") altered both ACD (polarization of Numb in dividing cells) and effector:memory ratios in our in vitro study (98). The loss of ICAM-1 also correlates with disruption in ACD and alterations in T cell fate (94), although the multifaceted role of ICAM-1 in effector and memory differentiation (114) complicates interpretation of this observation. Even the phenotypes from direct deletion of a polarity protein must be interpreted with caution, as these effects might be attributed to either ACD or the role of polarity proteins in the formation and 


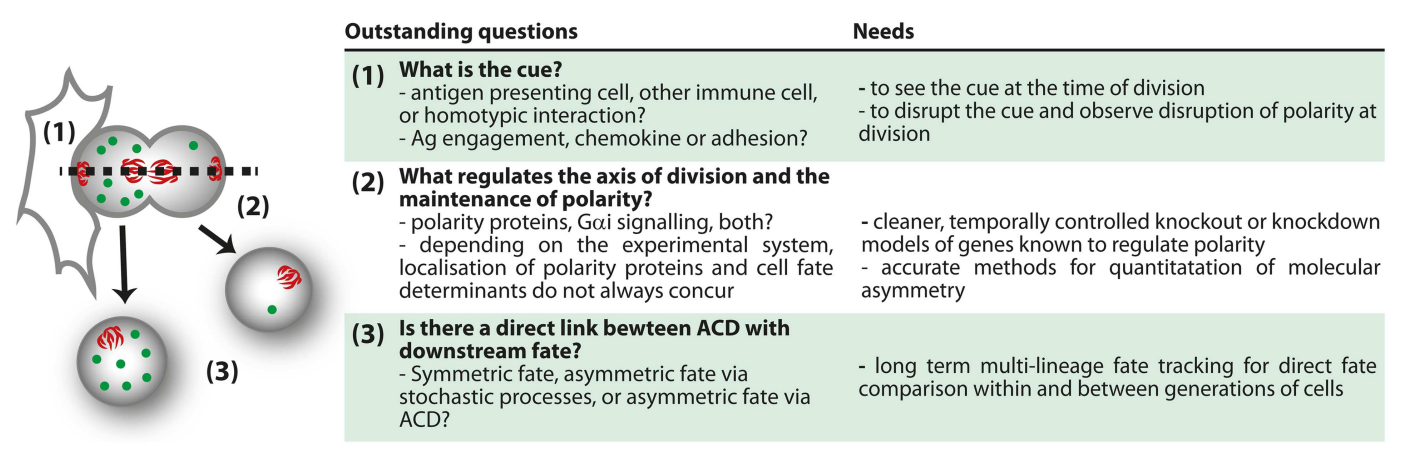

FIGURE 4 | Outstanding questions for ACD.

function of the immunological synapse and downstream signaling $(70,76,89,90,105)$. More acute knockouts, identification of genes that influence polarity at mitosis but not earlier (perhaps by regulating spindle orientation), and more extensive correlations of asymmetry and fate are required to fill these gaps in our knowledge (Figure 4).

Ultimately, definitive evidence of the impact of ACD on fate determination in lymphocytes will require more extensive integration of the three aspects of ACD, such that bifurcation of fate and polarity at division can be directly correlated. Several factors need to be taken into account in this endeavor. First, evidence to date suggests that ACD of lymphocytes is not uniformly adopted, but seems to arise in a fraction of the cells measured. Disruption of ACD would most likely impact upon some, but not all, the progeny of the population. Second, given the complexity of lymphocyte fate determination, and the many external cues that can influence lymphocyte fate determination, it seems that ACD of lymphocytes would more likely modify than determine fate decisions. Third, fate choices in lymphocytes often emerge incrementally over several generations, so measurements of the fate decisions made by each daughter cell must also be performed over a protracted period of time.

Such studies are now conceivable using in vitro approaches. Time lapse imaging of the process of division has been performed (95), and this type of approach can now take advantage of the rapid development in methods of quantification and duration of imaging (115-119). With these tools, it will be possible to directly observe how asymmetry at division can impact upon lymphocyte fate determination. Although it is unlikely that in vivo imaging will enable long-term fate tracking in the near future, the ability to observe cells over several hours $(99,100)$, and to track protein distribution (120) in vivo, will yield important information regarding the physiological context in which ACD can be observed. These approaches, combined with others such as the long-term in vitro time lapse imaging and the ex vivo analysis pioneered by the Reiner group (94), will together enable a comprehensive understanding of the mechanisms and roles of ACD in lymphocytes. The bulk of the research so far has been performed in $\mathrm{CD}^{+} \mathrm{T}$ cells, but many other aspects of lymphocyte differentiation and function might also involve ACD. Tracing the progeny of a single cell in vivo using approaches such as cellular barcoding, which have already provided evidence of fate bifurcation in the response of $\mathrm{CD} 8^{+} \mathrm{T}$ cells (85-87) are likely to yield important new information regarding the most physiologically relevant situations in which to look for ACD. Interestingly, a recent barcoding study argued against a clear bifurcation of fate in HSC (49). With the creation of more suitable knockout models, such as acute disruption of spindle orientation, new phenotypes might further highlight the systems in which ACD is most likely to play a physiological role (Figure 4). By combining all these approaches, a clearer picture of the mechanisms and consequences of ACD in lymphocytes is probably not too far away.

\section{AUTHOR CONTRIBUTIONS}

Kim Pham, Faruk Sacirbegovic, and Sarah M. Russell all wrote the manuscript.

\section{ACKNOWLEDGMENTS}

Kim Pham was supported by the NHRMC Biomedical Scholarship, Stem Cell Foundation and Swinburne University of Technology, Faruk Sacirbegovic was supported by the Melbourne Research Scholarship, Sarah M. Russell was supported by project grants and fellowships from NHMRC and ARC, and a Program grant from the HFSP. We thank members of the Russell lab for helpful discussions, and Patrick Humbert and Mohammed Yassin (PeterMac) for comments on the manuscript.

\section{REFERENCES}

1. Knoblich JA. Asymmetric cell division: recent developments and their implications for tumour biology. Nat Rev Mol Cell Biol (2010) 11(12):849-60. doi:10.1038/nrm3010

2. Gho M, Bellaiche Y, Schweisguth F. Revisiting the Drosophila microchaete lineage: a novel intrinsically asymmetric cell division generates a glial cell. Development (1999) 126(16):3573-84.

3. Morrison SJ, Kimble J. Asymmetric and symmetric stem-cell divisions in development and cancer. Nature (2006) 441(7097):1068-74. doi:10.1038/ nature 04956

4. Zhong W, Feder JN, Jiang MM, Jan LY, Jan YN. Asymmetric localization of a mammalian Numb homolog during mouse cortical neurogenesis. Neuron (1996) 17(1):43-53. doi:10.1016/S0896-6273(00)80279-2

5. Potten CS, Booth C, Pritchard DM. The intestinal epithelial stem cell: the mucosal governor. Int J Exp Pathol (1997) 78(4):219-43. doi:10.1046/j.13652613.1997.280362.x 
6. Loeffler M, Bratke T, Paulus U, Li YQ, Potten CS. Clonality and life cycles of intestinal crypts explained by a state dependent stochastic model of epithelial stem cell organization. J Theor Biol (1997) 186(1):41-54. doi:10.1006/jtbi. 1996.0340

7. Lechler T, Fuchs E. Asymmetric cell divisions promote stratification and differentiation of mammalian skin. Nature (2005) 437(7056):275-80. doi:10.1038/ nature 03922

8. Kuang S, Gillespie MA, Rudnicki MA. Niche regulation of muscle satellite cell self-renewal and differentiation. Cell Stem Cell (2008) 2(1):22-31. doi:10.1016/j.stem.2007.12.012

9. Colaluca IN, Tosoni D, Nuciforo P, Senic-Matuglia F, Galimberti V, Viale G, et al. Numb controls p53 tumour suppressor activity. Nature (2008) 451(7174):76-80. doi:10.1038/nature06412

10. Cicalese A, Bonizzi G, Pasi CE, Faretta M, Ronzoni S, Giulini B, et al. The tumor suppressor p53 regulates polarity of self-renewing divisions in mammary stem cells. Cell (2009) 138(6):1083-95. doi:10.1016/j.cell.2009.06.048

11. Faubert A, Lessard J, Sauvageau G. Are genetic determinants of asymmetric stem cell division active in hematopoietic stem cells? Oncogene (2004) 23(43):7247-55. doi:10.1038/sj.onc.1207944

12. Wu JC, Rose LS. PAR-3 and PAR-1 inhibit LET-99 localization to generate a cortical band important for spindle positioning in Caenorhabditis elegans embryos. Mol Biol Cell (2007) 18(11):4470-82. doi:10.1091/mbc.E07-02-0105

13. Sulston JE, Schierenberg E, White JG, Thomson JN. The embryonic cell lineage of the nematode Caenorhabditis elegans. Dev Biol (1983) 100(1):64-119. doi:10.1016/0012-1606(83)90201-4

14. Jenkins N, Saam JR, Mango SE. CYK-4/GAP provides a localized cue to initiate anteroposterior polarity upon fertilization. Science (2006) 313(5791):1298-301. doi:10.1126/science.1130291

15. Kirby C, Kusch M, Kemphues K. Mutations in the par genes of Caenorhabditis elegans affect cytoplasmic reorganization during the first cell cycle. Dev Biol (1990) 142(1):203-15. doi:10.1016/0012-1606(90)90164-E

16. Motegi F, Sugimoto A. Sequential functioning of the ECT-2 RhoGEF, RHO-1 and CDC-42 establishes cell polarity in Caenorhabditis elegans embryos. Nat Cell Biol (2006) 8(9):978-85. doi:10.1038/ncb1459

17. Schonegg S, Hyman AA. CDC-42 and RHO- 1 coordinate acto-myosin contractility and PAR protein localization during polarity establishment in C. elegans embryos. Development (2006) 133(18):3507-16. doi:10.1242/dev.02527

18. Watts JL, Morton DG, Bestman J, Kemphues KJ. The C. elegans par-4 gene encodes a putative serine-threonine kinase required for establishing embryonic asymmetry. Development (2000) 127(7):1467-75.

19. Lai EC, Orgogozo V. A hidden program in Drosophila peripheral neurogenesis revealed: fundamental principles underlying sensory organ diversity. Dev Biol (2004) 269(1):1-17. doi:10.1016/j.ydbio.2004.01.032

20. Udolph G, Rath P, Tio M, Toh J, Fang W, Pandey R, et al. On the roles of Notch, Delta, Kuzbanian, and Inscuteable during the development of Drosophila embryonic neuroblast lineages. Dev Biol (2009) 336(2):156-68. doi:10.1016/j.ydbio.2009.09.030

21. Okabe M, Imai T, Kurusu M, Hiromi Y, Okano H. Translational repression determines a neuronal potential in Drosophila asymmetric cell division. Nature (2001) 411(6833):94-8. doi:10.1038/35075094

22. Giebel B. Cell polarity and asymmetric cell division within human hematopoietic stem and progenitor cells. Cells Tissues Organs (2008) 188(1-2):116-26. doi:10.1159/000112842

23. Tsunekawa Y, Osumi N. How to keep proliferative neural stem/progenitor cells: a critical role of asymmetric inheritance of cyclin D2. Cell Cycle (2012) 11(19):3550-4. doi:10.4161/cc.21500

24. Wodarz A, Ramrath A, Grimm A, Knust E. Drosophila atypical protein kinase $\mathrm{C}$ associates with Bazooka and controls polarity of epithelia and neuroblasts. J Cell Biol (2000) 150(6):1361-74. doi:10.1083/jcb.150.6.1361

25. Wodarz A, Ramrath A, Kuchinke U, Knust E. Bazooka provides an apical cue for Inscuteable localization in Drosophila neuroblasts. Nature (1999) 402(6761):544-7. doi:10.1038/990128

26. Petronczki M, Knoblich JA. DmPAR-6 directs epithelial polarity and asymmetric cell division of neuroblasts in Drosophila. Nat Cell Biol (2001) 3(1):43-9. doi:10.1038/35050550

27. Bellaiche Y, Radovic A, Woods DF, Hough CD, Parmentier ML, O’Kane CJ, et al. The partner of Inscuteable/discs-large complex is required to establish planar polarity during asymmetric cell division in Drosophila. Cell (2001) 106(3):355-66. doi:10.1016/S0092-8674(01)00444-5
28. Siegrist SE, Doe CQ. Microtubule-induced Pins/Galphai cortical polarity in Drosophila neuroblasts. Cell (2005) 123(7):1323-35. doi:10.1016/j.cell.2005. 09.043

29. Wirtz-Peitz F, Nishimura T, Knoblich JA. Linking cell cycle to asymmetric division: aurora-A phosphorylates the par complex to regulate Numb localization. Cell (2008) 135(1):161-73. doi:10.1016/j.cell.2008.07.049

30. Lemaitre F, Moreau HD, Vedele L, Bousso P. Phenotypic CD8+ T cell diversification occurs before, during, and after the first $\mathrm{T}$ cell division. J Immunol (2013) 191(4):1578-85. doi:10.4049/jimmunol.1300424

31. Ohshiro T, Yagami T, Zhang C, Matsuzaki F. Role of cortical tumour-suppressor proteins in asymmetric division of Drosophila neuroblast. Nature (2000) 408(6812):593-6. doi:10.1038/35046087

32. Dar A, Goichberg P, Shinder V, Kalinkovich A, Kollet O, Netzer N, et al. Chemokine receptor CXCR4-dependent internalization and resecretion of functional chemokine SDF-1 by bone marrow endothelial and stromal cells. Nat Immunol (2005) 6(10):1038-46. doi:10.1038/ni1251

33. Lee CY, Robinson KJ, Doe CQ. Lgl, Pins and aPKC regulate neuroblast selfrenewal versus differentiation. Nature (2006) 439(7076):594-8. doi:10.1038/ nature04299

34. Rolls MM, Albertson R, Shih HP, Lee CY, Doe CQ. Drosophila aPKC regulates cell polarity and cell proliferation in neuroblasts and epithelia. J Cell Biol (2003) 163(5):1089-98. doi:10.1083/jcb.200306079

35. Smith CA, Lau KM, Rahmani Z, Dho SE, Brothers G, She YM, et al. aPKCmediated phosphorylation regulates asymmetric membrane localization of the cell fate determinant Numb. EMBO J (2007) 26(2):468-80. doi:10.1038/sj. emboj.7601495

36. Krummel MF, Macara I. Maintenance and modulation of T cell polarity. Nat Immunol (2006) 7(11):1143-9. doi:10.1038/ni1404

37. Audebert S, Navarro C, Nourry C, Chasserot-Golaz S, Lecine P, Bellaiche Y, et al. Mammalian Scribble forms a tight complex with the betaPIX exchange factor. Curr Biol (2004) 14(11):987-95. doi:10.1016/j.cub. 2004.05.051

38. Strome S, Wood WB. Generation of asymmetry and segregation of germ-line granules in early C. elegans embryos. Cell (1983) 35(1):15-25. doi:10.1016/ 0092-8674(83)90203-9

39. Rajewsky K. Clonal selection and learning in the antibody system. Nature (1996) 381(6585):751-8. doi:10.1038/381751a0

40. Hawkins ED, Russell SM. Upsides and downsides to polarity and asymmetric cell division in leukemia. Oncogene (2008) 27(55):7003-17. doi:10.1038/onc. 2008.350

41. Schober A, Wolf N, Kahane N, Kalcheim C, Krieglstein K, Unsicker K. Expression of neurotrophin receptors trkB and trkC and their ligands in rat adrenal gland and the intermediolateral column of the spinal cord. Cell Tissue Res (1999) 296(2):271-9. doi:10.1007/s004410051288

42. Wilson A, Ardiet DL, Saner C, Vilain N, Beermann F, Aguet M, et al. Normal hemopoiesis and lymphopoiesis in the combined absence of Numb and Numblike. J Immunol (2007) 178(11):6746-51.

43. Anderson AC, Kitchens EA, Chan SW, St Hill C, Jan YN, Zhong W, et al. The Notch regulator Numb links the Notch and TCR signaling pathways. J Immunol (2005) 174(2):890-7.

44. Petersen PH, Tang H, Zou K, Zhong W. The enigma of the NumbNotch relationship during mammalian embryogenesis. Dev Neurosci (2006) 28(1-2):156-68. doi:10.1159/000090761

45. Petersen PH, Zou K, Krauss S, Zhong W. Continuing role for mouse Numb and Numbl in maintaining progenitor cells during cortical neurogenesis. Nat Neurosci (2004) 7(8):803-11. doi:10.1038/nn1289

46. Petersen PH, Zou K, Hwang JK, Jan YN, Zhong W. Progenitor cell maintenance requires Numb and Numblike during mouse neurogenesis. Nature (2002) 419(6910):929-34. doi:10.1038/nature01124

47. Li HS, Wang D, Shen Q, Schonemann MD, Gorski JA, Jones KR, et al. Inactivation of Numb and Numblike in embryonic dorsal forebrain impairs neurogenesis and disrupts cortical morphogenesis. Neuron (2003) 40(6):1105-18. doi:10.1016/S0896-6273(03)00755-4

48. Osawa M, Hanada K, Hamada H, Nakauchi H. Long-term lymphohematopoietic reconstitution by a single CD34-low/negative hematopoietic stem cell. Science (1996) 273(5272):242-5. doi:10.1126/science.273.5272.242

49. Naik SH, Perie L, Swart E, Gerlach C, van Rooij N, de Boer RJ, et al. Diverse and heritable lineage imprinting of early haematopoietic progenitors. Nature (2013) 496(7444):229-32. doi:10.1038/nature12013 
50. Zhong W, Jiang MM, Schonemann MD, Meneses JJ, Pedersen RA, Jan LY, et al. Mouse Numb is an essential gene involved in cortical neurogenesis. Proc Natl Acad Sci U S A (2000) 97(12):6844-9. doi:10.1073/pnas.97.12.6844

51. Zhong W. Timing cell-fate determination during asymmetric cell divisions. Curr Opin Neurobiol (2008) 18(5):472-8. doi:10.1016/j.conb.2008.10.005

52. Wu M, Kwon HY, Rattis F, Blum J, Zhao C, Ashkenazi R, et al. Imaging hematopoietic precursor division in real time. Cell Stem Cell (2007) 1(5):541-54. doi:10.1016/j.stem.2007.08.009

53. Ting SB, Deneault E, Hope K, Cellot S, Chagraoui J, Mayotte N, et al. Asymmetric segregation and self-renewal of hematopoietic stem and progenitor cells with endocytic Ap2a2. Blood (2012) 119(11):2510-22. doi:10.1182/blood2011-11-393272

54. Berdnik D, Torok T, Gonzalez-Gaitan M, Knoblich JA. The endocytic protein alpha-adaptin is required for Numb-mediated asymmetric cell division in Drosophila. Dev Cell (2002) 3(2):221-31. doi:10.1016/S1534-5807(02)00215-0

55. Carvalho G, Poalas K, Demian C, Hatchi E, Vazquez A, Bidere N. Participation of the cell polarity protein PALS1 to T-cell receptor-mediated NF-kappaB activation. PLoS One (2011) 6(3):e18159. doi:10.1371/journal.pone.0018159

56. Sengupta A, Duran A, Ishikawa E, Florian MC, Dunn SK, Ficker AM, et al. Atypical protein kinase $\mathrm{C}$ (aPKCzeta and aPKClambda) is dispensable for mammalian hematopoietic stem cell activity and blood formation. Proc Natl Acad Sci U S A (2011) 108(24):9957-62. doi:10.1073/pnas.1103132108

57. Bultje RS, Castaneda-Castellanos DR, Jan LY, Jan YN, Kriegstein AR, Shi SH. Mammalian Par3 regulates progenitor cell asymmetric division via Notch signaling in the developing neocortex. Neuron (2009) 63(2):189-202. doi:10.1016/ j.neuron.2009.07.004

58. Heidel FH, Bullinger L, Arreba-Tutusaus P, Wang Z, Gaebel J, Hirt C, et al. The cell fate determinant Llgll influences HSC fitness and prognosis in AML. J Exp Med (2013) 210(1):15-22. doi:10.1084/jem.20120596

59. Duffy KR, Wellard CJ, Markham JF, Zhou JH, Holmberg R, Hawkins ED, et al. Activation-induced B cell fates are selected by intracellular stochastic competition. Science (2012) 335(6066):338-41. doi:10.1126/science.1213230

60. Kuchina A, Espinar L, Cagatay T, Balbin AO, Zhang F, Alvarado A, et al. Temporal competition between differentiation programs determines cell fate choice. Mol Syst Biol (2011) 7:557. doi:10.1038/msb.2011.88

61. Germain RN. The art of the probable: system control in the adaptive immune system. Science (2001) 293(5528):240-5. doi:10.1126/science.1062946

62. Cedar H, Bergman Y. Epigenetics of haematopoietic cell development. Nat Rev Immunol (2011) 11(7):478-88. doi:10.1038/nri2991

63. Hawkins E, Oliaro J, Kallies A, Belz GT, Filby A, Hogan T, et al. Regulation of asymmetric cell division and polarity by Scribble is not required for humoral immunity. Nat Commun (2013) 4:1801. doi:10.1038/ncomms2796

64. Yamashita YM, Fuller MT. Asymmetric centrosome behavior and the mechanisms of stem cell division. J Cell Biol (2008) 180(2):261-6. doi:10.1083/jcb. 200707083

65. Thaunat O, Granja AG, Barral P, Filby A, Montaner B, Collinson L, et al. Asymmetric segregation of polarized antigen on $\mathrm{B}$ cell division shapes presentation capacity. Science (2012) 335(6067):475-9. doi:10.1126/science.1214100

66. Takei K, Haucke V. Clathrin-mediated endocytosis: membrane factors pull the trigger. Trends Cell Biol (2001) 11(9):385-91. doi:10.1016/S0962-8924(01) 02082-7

67. Le Borgne R, Schweisguth F. Unequal segregation of neuralized biases Notch activation during asymmetric cell division. Dev Cell (2003) 5(1):139-48. doi:10.1016/S1534-5807(03)00187-4

68. Humphries LA, Shaffer MH, Sacirbegovic F, Tomassian T, McMahon KA, Humbert PO, et al. Characterization of in vivo Dlgl deletion on $\mathrm{T}$ cell development and function. PLoS One (2012) 7(9):e45276. doi:10.1371/journal.pone. 0045276

69. Sandoval GJ, Graham DB, Gmyrek GB, Akilesh HM, Fujikawa K, Sammut B, et al. Novel mechanism of tumor suppression by polarity gene discs large 1 (DLG1) revealed in a murine model of pediatric B-ALL. Cancer Immunol Res (2013) 1(6):1-12. doi:10.1158/2326-6066.CIR-13-0065

70. Liu W, Chen E, Zhao XW, Wan ZP, Gao YR, Davey A, et al. The scaffolding protein synapse-associated protein 97 is required for enhanced signaling through isotype-switched IgG memory B cell receptors. Sci Signal (2012) 5(235):ra54. doi:10.1126/scisignal.2002820

71. Dow LE, Elsum IA, King CL, Kinross KM, Richardson HE, Humbert PO Loss of human Scribble cooperates with H-Ras to promote cell invasion through deregulation of MAPK signalling. Oncogene (2008) 27(46):5988-6001. doi:10.1038/onc.2008.219

72. Pearson HB, Perez-Mancera PA, Dow LE, Ryan A, Tennstedt P, Bogani D, et al. SCRIB expression is deregulated in human prostate cancer, and its deficiency in mice promotes prostate neoplasia. J Clin Invest (2011) 121(11):4257-67. doi:10.1172/JCI58509

73. Nagasaka K, Pim D, Massimi P, Thomas M, Tomaic V, Subbaiah VK, et al. The cell polarity regulator hScrib controls ERK activation through a KIM sitedependent interaction. Oncogene (2010) 29(38):5311-21. doi:10.1038/onc. 2010.265

74. Metcalf D, Wiadrowski M. Autoradiographic analysis of lymphocyte proliferation in the thymus and in thymic lymphoma tissue. Cancer Res (1966) 26(3):483-91.

75. Sugimoto M, Yasuda T. Asymmetric (differential) cell division of thymic lymphocytes by means of cytoplasmic polarization: possible biological meanings. Thymus (1983) 5(5-6):297-310.

76. Joshi NS, Cui W, Chandele A, Lee HK, Urso DR, Hagman J, et al. Inflammation directs memory precursor and short-lived effector CD8(+) T cell fates via the graded expression of T-bet transcription factor. Immunity (2007) 27(2):281-95. doi:10.1016/j.immuni.2007.07.010

77. Pike KA, Kulkarni S, Pawson T. Immature T-cell clustering and efficient differentiation require the polarity protein Scribble. Proc Natl Acad Sci U S A (2011) 108(3):1116-21. doi:10.1073/pnas.1018224108

78. Ludford-Menting MJ, Oliaro J, Sacirbegovic F, Cheah ET, Pedersen N, Thomas $\mathrm{SJ}$, et al. A network of PDZ-containing proteins regulates $\mathrm{T}$ cell polarity and morphology during migration and immunological synapse formation. Immunity (2005) 22(6):737-48. doi:10.1016/j.immuni.2005.04.009

79. Aguado R, Martin-Blanco N, Caraballo M, Canelles M. The endocytic adaptor Numb regulates thymus size by modulating pre-TCR signaling during asymmetric division. Blood (2010) 116(10):1705-14. doi:10.1182/blood-2009-10246777

80. Yamane H, Paul WE. Early signaling events that underlie fate decisions of naive CD4(+) T cells toward distinct T-helper cell subsets. Immunol Rev (2013) 252(1):12-23. doi:10.1111/imr.12032

81. Ahmed R, Bevan MJ, Reiner SL, Fearon DT. The precursors of memory: models and controversies. Nat Rev Immunol (2009) 9(9):662-8. doi:10.1038/ nri2619

82. Restifo NP, Gattinoni L. Lineage relationship of effector and memory T cells. Curr Opin Immunol (2013) 25(5):556-63. doi:10.1016/j.coi.2013.09.003

83. Kaech SM, Cui W. Transcriptional control of effector and memory CD8+ T cell differentiation. Nat Rev Immunol (2012) 12(11):749-61. doi:10.1038/nri3307

84. Buchholz VR, Graf P, Busch DH. The smallest unit: effector and memory CD8(+) T cell differentiation on the single cell level. Front Immunol (2013) 4:31. doi:10.3389/fimmu.2013.00031

85. Gerlach C, Rohr JC, Perie L, van Rooij N, van Heijst JW, Velds A, et al. Heterogeneous differentiation patterns of individual CD8+ T cells. Science (2013) 340(6132):635-9. doi:10.1126/science.1235487

86. Buchholz VR, Flossdorf M, Hensel I, Kretschmer L, Weissbrich B, Graf P, et al. Disparate individual fates compose robust CD8+ T cell immunity. Science (2013) 340(6132):630-5. doi:10.1126/science.1235454

87. Plumlee CR, Sheridan BS, Cicek BB, Lefrancois L. Environmental cues dictate the fate of individual CD8 $(+) \mathrm{T}$ cells responding to infection. Immunity (2013) 39(2):347-56. doi:10.1016/j.immuni.2013.07.014

88. Miletic AV, Graham DB, Sakata-Sogawa K, Hiroshima M, Hamann MJ, Cemerski $S$, et al. Vav links the $\mathrm{T}$ cell antigen receptor to the actin cytoskeleton and $\mathrm{T}$ cell activation independently of intrinsic guanine nucleotide exchange activity. PLoS One (2009) 4(8):e6599. doi:10.1371/journal.pone.0006599

89. Round JL, Humphries LA, Tomassian T, Mittelstadt P, Zhang M, Miceli MC. Scaffold protein Dlgh 1 coordinates alternative $\mathrm{p} 38$ kinase activation, directing $\mathrm{T}$ cell receptor signals toward NFAT but not NF-kappaB transcription factors. Nat Immunol (2007) 8(2):154-61. doi:10.1038/ni1422

90. Round JL, Tomassian T, Zhang M, Patel V, Schoenberger SP, Miceli MC. Dlgh1 coordinates actin polymerization, synaptic $\mathrm{T}$ cell receptor and lipid raft aggregation, and effector function in T cells. J Exp Med (2005) 201(3):419-30. doi:10.1084/jem.20041428

91. Yeh JH, Sidhu SS, Chan AC. Regulation of a late phase of T cell polarity and effector functions by Crtam. Cell (2008) 132(5):846-59. doi:10.1016/j. cell.2008.01.013 
92. Xavier R, Rabizadeh S, Ishiguro K, Andre N, Ortiz JB, Wachtel H, et al. Discs large (Dlg1) complexes in lymphocyte activation. J Cell Biol (2004) 166(2):173-8. doi:10.1083/jcb.200309044

93. Bertrand F, Esquerre M, Petit AE, Rodrigues M, Duchez S, Delon J, et al. Activation of the ancestral polarity regulator protein kinase $\mathrm{C}$ zeta at the immunological synapse drives polarization of Th cell secretory machinery toward APCs. J Immunol (2010) 185(5):2887-94. doi:10.4049/jimmunol. 1000739

94. Chang JT, Palanivel VR, Kinjyo I, Schambach F, Intlekofer AM, Banerjee A, et al. Asymmetric T lymphocyte division in the initiation of adaptive immune responses. Science (2007) 315(5819):1687-91. doi:10.1126/ science. 1139393

95. Chang JT, Ciocca ML, Kinjyo I, Palanivel VR, McClurkin CE, Dejong CS, et al. Asymmetric proteasome segregation as a mechanism for unequal partitioning of the transcription factor T-bet during T lymphocyte division. Immunity (2011) 34(4):492-504. doi:10.1016/j.immuni.2011.03.017

96. Ciocca ML, Barnett BE, Burkhardt JK, Chang JT, Reiner SL. Cutting edge: asymmetric memory $\mathrm{T}$ cell division in response to rechallenge. J Immunol (2012) 188(9):4145-8. doi:10.4049/jimmunol.1200176

97. King CG, Koehli S, Hausmann B, Schmaler M, Zehn D, Palmer E. T cell affinity regulates asymmetric division, effector cell differentiation, and tissue pathology. Immunity (2012) 37(4):709-20. doi:10.1016/j.immuni.2012.06.021

98. Oliaro J, Van Ham V, Sacirbegovic F, Pasam A, Bomzon Z, Pham K, et al. Asymmetric cell division of $\mathrm{T}$ cells upon antigen presentation uses multiple conserved mechanisms. J Immunol (2010) 185(1):367-75. doi:10.4049/jimmunol. 0903627

99. Henrickson SE, Perro M, Loughhead SM, Senman B, Stutte S, Quigley M, et al. Antigen availability determines CD8(+) T cell-dendritic cell interaction kinetics and memory fate decisions. Immunity (2013) 39(3):496-507. doi:10.1016/j.immuni.2013.08.034

100. Mempel TR, Henrickson SE, Von Andrian UH. T-cell priming by dendritic cells in lymph nodes occurs in three distinct phases. Nature (2004) 427(6970):154-9. doi:10.1038/nature02238

101. Gerard A, Khan O, Beemiller P, Oswald E, Hu J, Matloubian M, et al. Secondary T cell-T cell synaptic interactions drive the differentiation of protective CD8(+) T cells. Nat Immunol (2013) 14(4):356-63. doi:10.1038/ni.2547

102. Thaventhiran JE, Hoffmann A, Magiera L, de la Roche M, Lingel H, BrunnerWeinzierl M, et al. Activation of the hippo pathway by CTLA-4 regulates the expression of Blimp-1 in the CD8+ T cell. Proc Natl Acad Sci U S A (2012) 109(33):E2223-9. doi:10.1073/pnas.1209115109

103. Tkach K, Altan-Bonnet G. T cell responses to antigen: hasty proposals resolved through long engagements. Curr Opin Immunol (2013) 25(1):120-5. doi:10.1016/j.coi.2012.12.001

104. Lasserre R, Charrin S, Cuche C, Danckaert A, Thoulouze MI, de Chaumont F, et al. Ezrin tunes T-cell activation by controlling Dlg1 and microtubule positioning at the immunological synapse. EMBO J (2010) 29(14):2301-14. doi:10.1038/emboj.2010.127

105. Zanin-Zhorov A, Lin J, Scher J, Kumari S, Blair D, Hippen KL, et al. Scaffold protein Disc large homolog 1 is required for T-cell receptor-induced activation of regulatory T-cell function. Proc Natl Acad Sci U S A (2012) 109(5):1625-30. doi:10.1073/pnas.1110120109

106. Real E, Faure S, Donnadieu E, Delon J. Cutting edge: atypical PKCs regulate T lymphocyte polarity and scanning behavior. J Immunol (2007) 179(9): 5649-52.

107. Soloff RS, Katayama C, Lin MY, Feramisco JR, Hedrick SM. Targeted deletion of protein kinase $\mathrm{C}$ lambda reveals a distribution of functions between the two atypical protein kinase C isoforms. J Immunol (2004) 173(5):3250-60.

108. Martin P, Villares R, Rodriguez-Mascarenhas S, Zaballos A, Leitges M, Kovac $\mathrm{J}$, et al. Control of $\mathrm{T}$ helper 2 cell function and allergic airway inflammation by PKCzeta. Proc Natl Acad Sci U S A (2005) 102(28):9866-71. doi:10.1073/pnas.0501202102

109. Yang JQ, Leitges M, Duran A, Diaz-Meco MT, Moscat J. Loss of PKC lambda/iota impairs Th2 establishment and allergic airway inflammation in vivo. Proc Natl Acad Sci U S A (2009) 106(4):1099-104. doi:10.1073/pnas. 0805907106

110. Martin P, Moscat J. Th1/Th2 differentiation and B cell function by the atypical PKCs and their regulators. Front Immunol (2012) 3:241. doi:10.3389/fimmu. 2012.00241
111. Lin J, Hou KK, Piwnica-Worms H, Shaw AS. The polarity protein Par1b/EMK/MARK2 regulates $\mathrm{T}$ cell receptor-induced microtubuleorganizing center polarization. J Immunol (2009) 183(2):1215-21. doi:10. 4049/jimmunol.0803887

112. Hurov JB, Stappenbeck TS, Zmasek CM, White LS, Ranganath SH, Russell $\mathrm{JH}$, et al. Immune system dysfunction and autoimmune disease in mice lacking Emk (Par-1) protein kinase. Mol Cell Biol (2001) 21(9):3206-19. doi:10.1128/MCB.21.9.3206-3219.2001

113. Gmyrek GB, Graham DB, Sandoval G, Blaufuss GS, Akilesh HM, Fujikawa $\mathrm{K}$, et al. Polarity gene discs large homolog 1 regulates the generation of memory T cells. Eur J Immunol (2013) 43(5):1185-94. doi:10.1002/eji. 201142362

114. Cox MA, Barnum SR, Bullard DC, Zajac AJ. ICAM-1-dependent tuning of memory CD8 T-cell responses following acute infection. Proc Natl Acad Sci U S A (2013) 110(4):1416-21. doi:10.1073/pnas.1213480110

115. Lecault V, Vaninsberghe M, Sekulovic S, Knapp DJ, Wohrer S, Bowden W, et al. High-throughput analysis of single hematopoietic stem cell proliferation in microfluidic cell culture arrays. Nat Methods (2011) 8(7):581-6. doi: $10.1038 /$ nmeth. 1614

116. Rowat AC, Bird JC, Agresti JJ, Rando OJ, Weitz DA. Tracking lineages of single cells in lines using a microfluidic device. Proc Natl Acad Sci U S A (2009) 106(43):18149-54. doi:10.1073/pnas.0903163106

117. Pham K, Shimoni R, Ludford-Menting MJ, Nowell CJ, Lobachevsky P, Bomzon $\mathrm{Z}$, et al. Divergent lymphocyte signalling revealed by a powerful new tool for analysis of time-lapse microscopy. Immunol Cell Biol (2013) 91(1):70-81. doi:10.1038/icb.2012.49

118. Day D, Pham K, Ludford-Menting MJ, Oliaro J, Izon D, Russell SM, et al. A method for prolonged imaging of motile lymphocytes. Immunol Cell Biol (2009) 87(2):154-8. doi:10.1038/icb.2008.79

119. Zaretsky I, Polonsky M, Shifrut E, Reich-Zeliger S, Antebi Y, Aidelberg G, et al. Monitoring the dynamics of primary $\mathrm{T}$ cell activation and differentiation using long term live cell imaging in microwell arrays. Lab Chip (2012) 12(23):5007-15. doi:10.1039/c2lc40808b

120. Melichar HJ, Li O, Herzmark P, Padmanabhan RK, Oliaro J, Ludford-Menting MJ, et al. Quantifying subcellular distribution of fluorescent fusion proteins in cells migrating within tissues. Immunol Cell Biol (2011) 89(4):549-57. doi:10.1038/icb.2010.122

121. Bilder D, Perrimon N. Localization of apical epithelial determinants by the basolateral PDZ protein Scribble. Nature (2000) 403(6770):676-80. doi:10. $1038 / 35001108$

122. Muller HA, Wieschaus E. Armadillo, bazooka, and stardust are critical for early stages in formation of the zonula adherens and maintenance of the polarized blastoderm epithelium in Drosophila. J Cell Biol (1996) 134(1):149-63. doi:10.1083/jcb.134.1.149

123. Bellaiche Y, Gho M, Kaltschmidt JA, Brand AH, Schweisguth F. Frizzled regulates localization of cell-fate determinants and mitotic spindle rotation during asymmetric cell division. Nat Cell Biol (2001) 3(1):50-7. doi:10.1038/ 35050558

124. Huynh JR, Petronczki M, Knoblich JA, St Johnston D. Bazooka and PAR-6 are required with PAR-1 for the maintenance of oocyte fate in Drosophila. Curr Biol (2001) 11(11):901-6. doi:10.1016/S0960-9822(01)00244-5

125. Suzuki A, Yamanaka T, Hirose T, Manabe N, Mizuno K, Shimizu M, et al. Atypical protein kinase $\mathrm{C}$ is involved in the evolutionarily conserved par protein complex and plays a critical role in establishing epithelia-specific junctional structures. J Cell Biol (2001) 152(6):1183-96. doi:10.1083/jcb.152. 6.1183

126. Fung I, Russell SM, Oliaro J. Interplay of polarity proteins and GTPases in T-lymphocyte function. Clin Dev Immunol (2012) 2012:417485. doi:10.1155/ 2012/417485

127. Giagulli C, Scarpini E, Ottoboni L, Narumiya S, Butcher EC, Constantin G, et al. RhoA and zeta PKC control distinct modalities of LFA-1 activation by chemokines: critical role of LFA-1 affinity triggering in lymphocyte in vivo homing. Immunity (2004) 20(1):25-35. doi:10.1016/S10747613(03)00350-9

128. Tepass U, Theres C, Knust E. Crumbs encodes an EGF-like protein expressed on apical membranes of Drosophila epithelial cells and required for organization of epithelia. Cell (1990) 61(5):787-99. doi:10.1016/00928674(90)90189-L 
129. Roh MH, Fan S, Liu CJ, Margolis B. The Crumbs3-Pals1 complex participates in the establishment of polarity in mammalian epithelial cells. J Cell Sci (2003) 116(Pt 14):2895-906. doi:10.1242/jcs.00500

130. Tepass U, Knust E. Crumbs and stardust act in a genetic pathway that controls the organization of epithelia in Drosophila melanogaster. Dev Biol (1993) 159(1):311-26. doi:10.1006/dbio.1993.1243

131. Woods DF, Bryant PJ. Molecular cloning of the lethal(1)discs large-1 oncogene of Drosophila. Dev Biol (1989) 134(1):222-35. doi:10.1016/0012-1606(89) 90092-4

132. Musch A, Cohen D, Yeaman C, Nelson WJ, Rodriguez-Boulan E, Brennwald PJ. Mammalian homolog of Drosophila tumor suppressor lethal (2) giant larvae interacts with basolateral exocytic machinery in Madin-Darby canine kidney cells. Mol Biol Cell (2002) 13(1):158-68. doi:10.1091/mbc.0110-0496

133. Klezovitch O, Fernandez TE, Tapscott SJ, Vasioukhin V. Loss of cell polarity causes severe brain dysplasia in Lgll knockout mice. Genes Dev (2004) 18(5):559-71. doi:10.1101/gad.1178004
Conflict of Interest Statement: The authors declare that the research was conducted in the absence of any commercial or financial relationships that could be construed as a potential conflict of interest.

Received: 08 November 2013; accepted: 16 January 2014; published online: 03 February 2014.

Citation: Pham K, Sacirbegovic F and Russell SM (2014) Polarized cells, polarized views: asymmetric cell division in hematopoietic cells. Front. Immunol. 5:26. doi: 10.3389/fimmu.2014.00026

This article was submitted to T Cell Biology, a section of the journal Frontiers in Immunology.

Copyright (c) 2014 Pham, Sacirbegovic and Russell. This is an open-access article distributed under the terms of the Creative Commons Attribution License (CC BY). The use, distribution or reproduction in other forums is permitted, provided the original author(s) or licensor are credited and that the original publication in this journal is cited, in accordance with accepted academic practice. No use, distribution or reproduction is permitted which does not comply with these terms. 